\title{
DESENHO DE UMA METODOLOGIA DE INTERVENÇ̃̃̃O A DISTÂNCIA PARA APROPRIAÇÃO E USO DOS MAPAS CONCEITUAIS EM ATIVIDADES EDUCACIONAIS
}

\begin{abstract}
Resumo. Este trabalho apresenta o desenho de uma metodologia de intervenção interativa a distância que visa a potencialização de espaços de aprendizagem coletivas disponibilizados por um portal educacional que visa a apropriação e uso de uma abordagem construtivista dos mapas conceituais. Os resultados desta pesquisa consistem em um conjunto de atividades e procedimentos utilizados bem como a descrição das condutas adotadas pelos docentes nas intervenções a distância. Tais condutas estão categorizadas tanto em relação aos dispositivos usados quanto em relação ao feedback dos educadores em formação nos cursos. Palavras-chave: educação a distância, mapas conceituais, formação continuada e metodologia de intervenção.
\end{abstract}

\section{Apresentação}

O Laboratório de Estudos em Educação a Distância (Le@d.CAp), grupo de pesquisa da UFRGS, tem desenvolvido investigação sobre os fundamentos psicológicos e epistemológicos da construção e reconstrução de mapas conceituais em atividades educacionais. Essa investigação tem gerado resultados que permitiram a elaboração de modelos e métodos de análise dos mapas conceituais (Dutra, Fagundes \& Cañas, 2004) fazendo uso da Epistemologia Genética de Jean Piaget (Piaget, 1990) e da Lógica Natural de Jean-Blaise Grize (Grize, 1996, 1997). Tal abordagem implicou a produção de um conjunto de critérios de análise dos processos de conceituação utilizando uma seqüência temporal de Mapas Conceituais de um mesmo sujeito sobre um mesmo assunto (Dutra, 2006).

A equipe do Le@d.CAp, através do Portal Mapas Conceituais na Educação (Portal MCE) vem oferecendo, desde 2003, experiências de trabalho em rede construídas segundo modelos que privilegiam um aprofundamento das discussões em torno de práticas educacionais com foco na aprendizagem de conceitos. Profissionais e estudantes que se interessam em fazer uso dos Mapas Conceituais para o acompanhamento e avaliação da aprendizagem usando uma abordagem teórica construtivista encontram no Portal MCE um espaço de discussão e compartilhamento de idéias que privilegiam a interação entre os participantes como principal forma de propiciar aprendizagens.

Como conseqüência, a divulgação e o aprimoramento das investigações que levaram ao modelo desenvolvido por esse grupo de pesquisa encontra nos cursos a distância oferecidos à comunidade de participantes do Portal MCE um espaço privilegiado de testagem e observação no sentido de obter dados que permitam verificar sua eficácia. Por essa razão, nos cabe analisar os resultados obtidos em tais cursos de forma a identificar e sistematizar, na forma de método, o conjunto de fatores que foram capazes de produzir intervenções eficazes fazendo uso dos dispositivos de interação disponíveis em cada caso. O suporte oferecido pelos ambientes e dispositivos de 
interação virtuais, tais como chats, fóruns, lista de e-mails e blogs, possibilita o registro das atividades realizadas e interações promovidas, o que permite, portanto a análise e classificação de tais registros.

Apresentaremos, a seguir, uma breve contextualização do ferramental teórico e das ações empreendidas através do Portal MCE para, depois, mostrar os resultados e considerações obtidos a partir da análise dos materiais e orientações disponibilizadas em cada curso, bem como dos registros das participações dos cursistas e docentes.

\section{Os mapas conceituais, o Portal MCE e os cursos analisados}

A técnica de construção e a teoria a respeito dos Mapas Conceituais foi desenvolvida pelo pesquisador norte-americano Joseph Novak (Novak \& Gowin, 1984). Ele define mapa conceitual como uma ferramenta para organizar e representar conhecimento. $\mathrm{O}$ mapa conceitual, baseado na teoria da aprendizagem significativa de David Ausubel (Ausubel, 2000), é uma representação gráfica em duas dimensões de um conjunto de conceitos construídos de tal forma que as relações entre eles sejam evidentes. Os conceitos aparecem dentro de caixas nos nós do grafo enquanto que as relações entre os conceitos são especificadas através de frases de ligação nos arcos que unem os conceitos. A dois ou mais conceitos, conectados por frases de ligação criando uma unidade semântica, chamamos de proposição. As proposições são uma característica particular dos mapas conceituais se comparados a outros grafos similares como os mapas mentais.

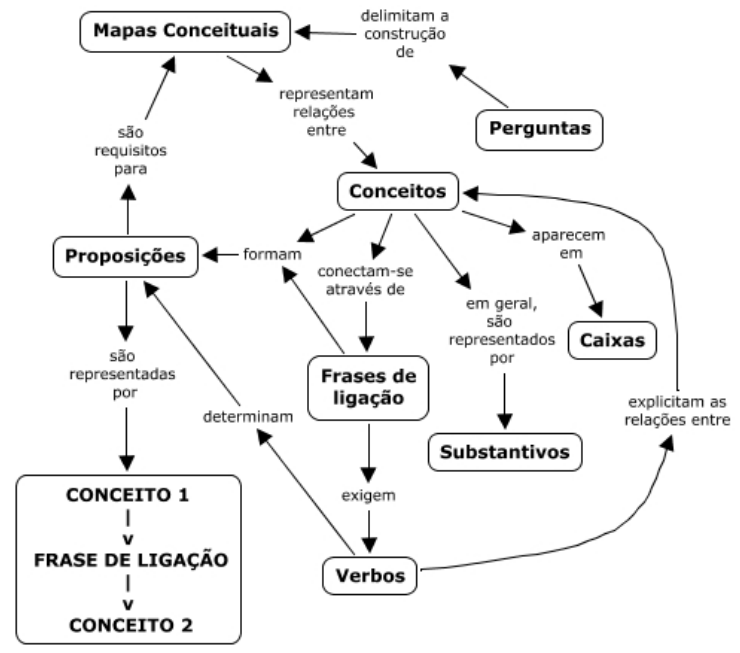

Figura 1. Mapa Conceitual sobre Mapas Conceituais

O Portal MCE (http://mapasconceituais.cap.ufrgs.br) abriga uma série de funcionalidades que permitem a seus participantes contribuir, aprender e interagir de forma autônoma através da autoria compartilhada de atividades. A partir do momento em que um participante é cadastrado no portal, seu endereço eletrônico é automaticamente é incluído na Lista de Discussão vinculada. Através do endereço do correio eletrônico mapasconceituais@grupos.ufrgs.br, os participantes da lista dispõem de um meio rápido e eficiente para suscitar e efetivamente realizar discussões, bem 
como divulgar trabalhos, eventos e outras ações relacionadas ao uso dos Mapas Conceituais.

É ainda possível aos participantes ter acesso a recursos necessários para cadastrar uma atividade através de um Ambiente de Criação e Edição de Atividades (AÇAI) e, assim, constituir uma comunidade que pode incluir outros participantes cadastrados. Esse cadastro cria um espaço virtual, como uma espécie de blog, em que se visualiza sua finalidade, objetivos, estratégias e critérios de avaliação, além da motivação dos responsáveis. Além disso, é possível aos responsáveis fazer registros em um Diário de Bordo, onde se pode descrever as atividades realizadas, anexar arquivos, enviar imagens digitalizadas e cadastrar links relacionados. Outros participantes (cadastrados ou não no Portal) podem interagir com a atividade, enviando comentários aos diários ou à Comunidade como um todo.

Além dessas duas formas de interação entre os participantes do Portal, nos Fóruns é possível gerar discussões sobre questões específicas demandadas pela própria comunidade. Todo participante pode criar fóruns de discussão bem como se inserir em outras discussões propostas pelos colegas. As mensagens em um Fórum existente estão organizadas hierarquicamente com informações sobre o autor da mensagem, bem como quando foi postada. Ferramentas de busca permitem destacar as mensagens de acordo com critérios de data de postagem ou palavras-chave.

No espaço denominado Produções encontram-se os materiais produzidos pela comunidade que usa os Mapas Conceituais na Educação. Todo participante cadastrado pode enviar materiais de acordo com as categorias indicadas. Com uma ferramenta de busca, o usuário pode especificar a espécie de material que está à procura, desde artigos, textos, até mapas conceituais, apresentações etc.

\section{Método}

Os cursos oferecidos pelo Portal MCE e que foram analisados para a produção desse estudo foram desenvolvidos através das seguintes estratégias:

- os cursos tiveram curta duração (por volta de 3 ou 4 semanas com carga horária máxima de 60h);

- em todos eles, houve o suporte da lista de discussão do Portal para o envio das orientações e o saneamento de quaisquer dúvidas a respeito dos dispositivos empregados para as atividades;

- dois dos cursos analisados foram completamente realizados usando-se o blog disponível no próprio Portal: as orientações eram postadas como um diário de bordo assim como as produções dos cursistas (os arquivos de imagem gerados a partir dos mapas conceituais eram anexados a cada diário), e as interações e intervenções eram realizadas através dos Comentários a cada diário;

- outros dois cursos foram totalmente realizados usando-se o software CmapTools (Cañas et al, 1994, 2004) e um servidor de mapas conceituais (CMapServer) que permitem o compartilhamento via internet dos mapas bem como a possibilidade de abrigar Fios de discussão (fóruns de discussão online que podem ser anexados aos conceitos ou ligações de um mapa produzido no CmapTools e armazenado no servidor de mapas); 
- em um deles foi realizada uma videoconferência através do sistema Breeze da Macromedia disponível em servidor da UFRGS: além da transmissão de áudio e vídeo (bidirecional), era possível compartilhar documentos (apresentações em Powerpoint, figuras etc) e interagir através de chat.

O método empregado implicou a análise das atividades e das orientações para a sua realização, bem como das intervenções realizadas pelos docentes em contraste com as produções dos participantes dos cursos de forma a obter os princípios norteadores da produção das atividades bem como das intervenções realizadas (não apenas pelos docentes como também pela interação dos próprios participantes). Por essa razão entende-se por intervenção, para o contexto desse estudo, tanto a proposta de cada atividade em si quanto as interações de que participam docente $\leftarrow \rightarrow$ cursista ou àquelas que envolvem cursista $\leftarrow \rightarrow$ cursista.

\section{Resultados}

O método de trabalho para o desenvolvimento das atividades dos cursos consiste em propiciar trocas, apoiadas nos materiais e textos disponibilizados nesse ambiente, entre os participantes. Conseqüentemente, os registros produzidos por essas interações tornam-se a principal evidência das aprendizagens de cada um. Nessa perspectiva, a aferição de frequiência e a avaliação da participação estão vinculadas à quantidade e qualidade das participações que fiquem, efetivamente, registradas no ambiente, ou seja, a postagem de mensagens solicitadas em cada atividade, à participação nas interações síncronas e ao envio de material (em geral, mapas conceituais transformados em figuras).

O desenho inicial de cada curso oferecido pelo Portal MCE segue um conjunto de princípios que foram sistematizados no mapa conceitual da Figura 2 a seguir.

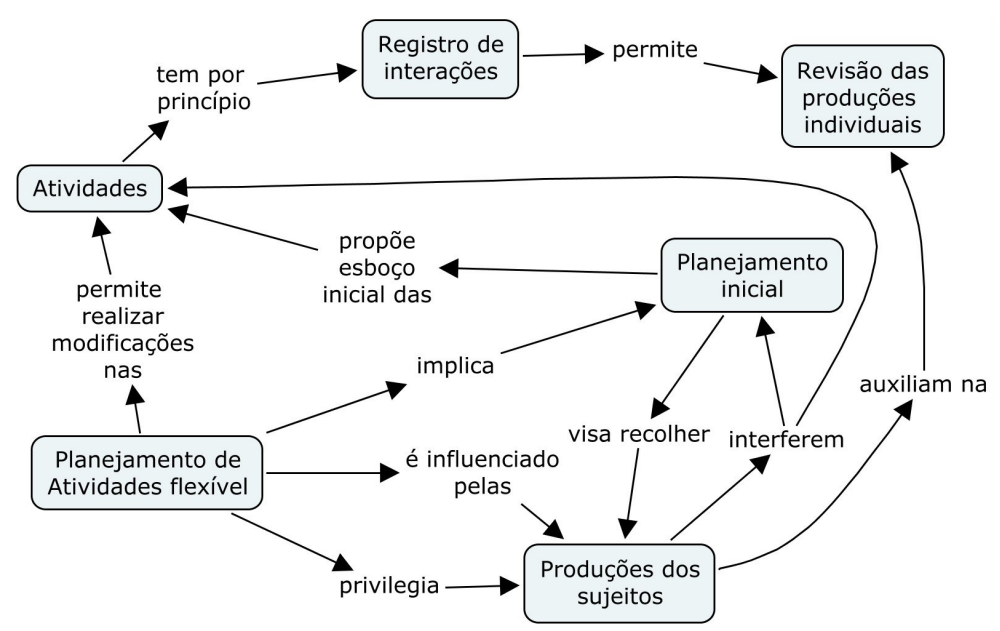

Figura 2. Princípios que regem o planejamento das atividades dos cursos no Portal MCE

Tomemos como exemplo, a seguinte seqüência de atividades produzidas para o Curso Abordagem Construtivista dos Mapas Conceituais (2007): 
- A primeira atividade consistiu na elaboração de um mapa conceitual (utilizando para isso o software CmapTools) que representasse a sua compreensão de cada um a respeito das diferenças entre as abordagens propostas pela aprendizagem significativa e a epistemologia genética. Para isso foram oferecidos dois textos: Mapas conceituais e aprendizagem significativa e Mapas conceituais e epistemologia genética. Em complemento foi solicitada a elaboração um texto que explicasse o mapa construído, esclarecendo e argumentando as proposições do mesmo. O texto e a figura do mapa conceitual foram postados no blog, individualmente.

- Na segunda atividade do curso solicitamos que cada participante entrevistasse dois colegas de sua turma a respeito dos mapas e textos produzidos por ambos. Esta entrevista foi realizada na sessão dos comentários de cada Diário tendo como objetivo obter dos colegas o seu ponto de vista a respeito de suas produções.

- Por fim, após a rodada de mensagens e a realização da videoconferência, foi solicitado que cada participante produzisse uma segunda versão do mapa conceitual construído na primeira atividade, bem como do texto explicativo relativo ao mesmo. Também foi solicitada uma avaliação das aprendizagens realizadas (auto-avaliação) bem como da metodologia empregada para a realização do curso incluindo sugestões de temas para possíveis novos cursos.

Estão presentes, nessa descrição de atividades, alguns dos aspectos destacados no mapa conceitual da Figura 2. A primeira atividade, ainda que absolutamente corriqueira, tinha a finalidade de obter registros dos participantes, na forma de mapa conceitual, que pudessem explicitar tanto a sua compreensão dos aspectos teóricos envolvidos nos textos quanto a sua habilidade em construir um mapa conceitual. $\mathrm{O}$ complemento à essa primeira ação dos cursistas, ou seja, a solicitação de um texto explicativo do mapa resultou da observação de atividades anteriores nas quais as intervenções tanto dos docentes quanto dos outros participantes do curso em geral não abrangiam a totalidade dos conceitos e sistemas de relação representados em cada mapa.

Já a segunda atividade pode ser considerada o principal foco da seqüência mostrada. As perguntas e respostas obtidas em cada rodada de entrevistas puderam ser contrastadas pelos próprios registros de cada diário. Ou seja, algumas vezes, a explicação que determinado cursista pedia ao seu colega já estava presente no texto explicativo constante no diário que continha o mapa. Outras vezes, o próprio participante dava-se conta de que a sua explicação ou o seu mapa poderia ser complementado ou estava pouco claro a partir da pergunta ou sugestão do outro colega. Como tudo isso estava registrado e poderia ser revisado quantas vezes fosse necessário, a sequiência de trocas permitiu, então, a proposta de revisão da primeira produção de cada cursista (o mapa conceitual) na terceira atividade.

Assim, no que tange às propostas de atividades como método de intervenção, os princípios descritos anteriormente (no mapa conceitual da Figura 2) regulam a sistemática de produção de material dos cursos no sentido de estabelecer, uma vez definidos os conteúdos a serem abordados, as estratégias de atuação tanto dos docentes quanto dos participantes. Podemos afirmar, portanto, que um planejamento de atividades flexível, privilegiando as análises das produções dos participantes dos cursos auxilia a realização de intervenções (tanto por parte dos docentes quanto por parte dos próprios cursistas). 
No segundo exemplo temos uma seqüência de extratos de Mapas Conceituais produzidos por um aluno participante do curso "Mapas Conceituais na Avaliação de Aprendizagem" (2005) e, entre eles, as intervenções realizadas tanto pelo docente quanto por outros participantes no sentido de modificar (aprimorar) tal produção.

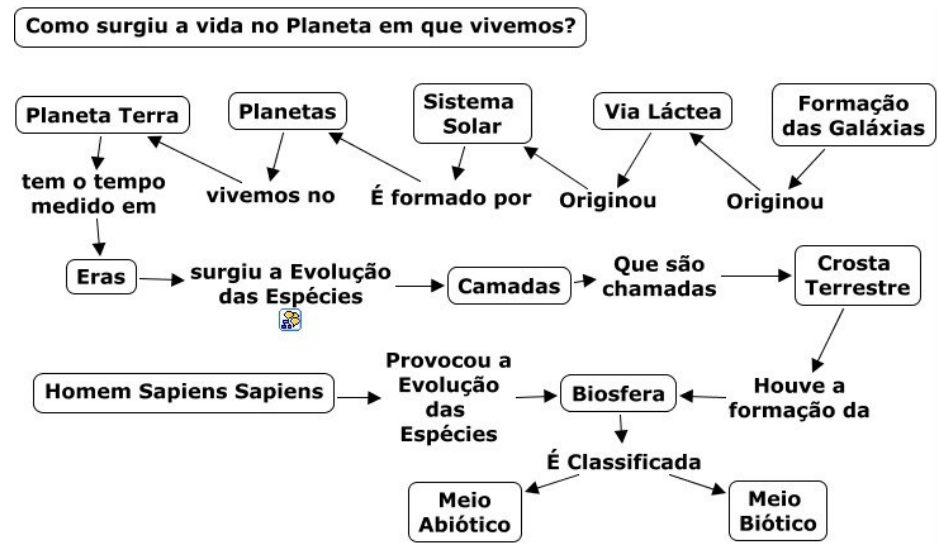

Figura 3. Mapa Conceitual produzido no dia 11/10/2005

Na Figura 3 pode-se observar a primeira versão do mapa conceitual construído por um participante do curso (professor universitário) sobre um assunto que o mesmo gostava e que, segundo ele, tinha algum conhecimento. Como o objetivo do curso estava direcionado ao uso dos mapas para a avaliação, as intervenções a seguir estão, evidentemente, buscando refletir tal objetivo. A primeira intervenção a respeito dessa produção e que será analisada a seguir foi feita pelo docente do curso.

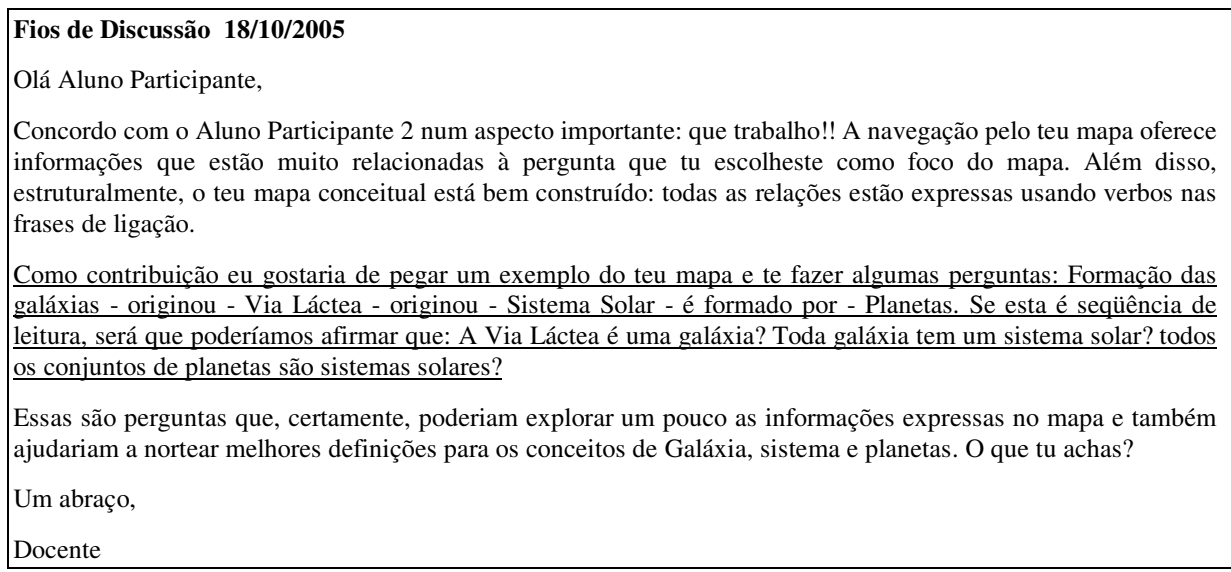

O texto sublinhado no quadro acima revela a escolha do docente que recai sobre um determinado setor (conjunto de relações) do mapa conceitual apresentado na Figura 3. Esse sistema de relações, que mais parece um texto que um mapa conceitual, é abordado pelo docente de forma a explorar as possibilidades de relações (logicamente plausíveis) entre os pares de conceitos. Isso significa dizer que cada conjunto conceitofrase de ligação-conceito pode ser testado isoladamente quanto à possibilidade de negação da proposição (Sistema Solar - é formado por - Planetas $\rightarrow$ todos os conjuntos de planetas são sistemas solares?), da troca de um dos conceitos ou, ainda, de 
estabelecer outra ligação entre os conceitos que ali aparecem. Também é possível explorar as combinações entre as proposições. O mapa conceitual a seguir mostra algumas das modificações feitas no mapa a partir da intervenção. As alterações foram realizadas principalmente nas frases de ligação na tentativa de responder aos questionamentos do docente.

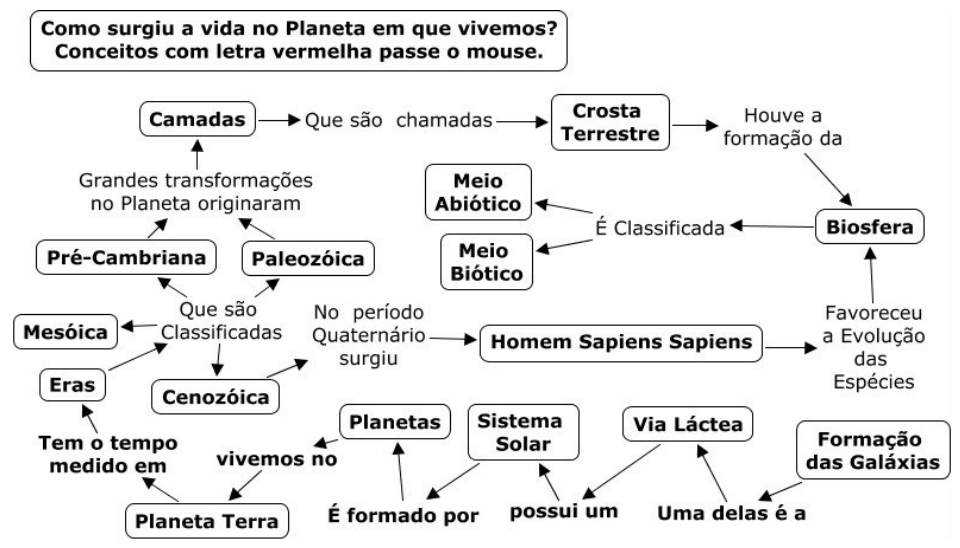

Figura 4. Mapa Conceitual produzido no dia 19/10/2005

O extrato a seguir, ainda que incipiente no que se refira à uma intervenção, mostra uma tomada de consciência de um outro participante do curso ao analisar a segunda versão do mapa conceitual da Figura 4.

Fios de Discussão 27/10/2005
Aluno Participante,
Esta nova apresentação que você fez, colocando mais conceitos e outras frases de ligação fez com o que seu mapa
ficasse mais claro. É impressionante como a construção de um MC não acaba nunca... Por melhor que esteja
sempre olhamos por uma nova ótica a cada vez que nos deparamos com ele.
Aluno Participante 2

Podemos observar uma tentativa do cursista em examinar um aspecto importante da construção de mapas conceituais que se refere justamente ao fato de que sempre é possível explorar as relações do mapa em uma freqüência que, como ela mesma afirma, "não acaba nunca". Decorre que se pode escolher arbitrariamente pontos específicos do mapa conceitual sobre os quais se pode fazer a intervenção uma vez que o foco incide no processo que leva à construção conceitual e não no mapa conceitual em si como um produto finalizado. Tais reflexões são importantes no sentido de que se espera de tais educadores uma aplicação dos conhecimentos construídos no curso de forma efetiva em suas práticas profissionais.

A análise dos dois exemplos deixa claro que os dispositivos (síncronos ou assíncronos) nos permitem fazer intervenções eficazes, ainda que sem grande sofisticação tecnológica (no sentido de que permitem principalmente trocas de textos).

\section{Conclusões}


A revisão de literatura atual a respeito de investigações sobre o uso dos mapas conceituais nos levaram a analisar o estudo de Cunha, Fernandes, Omar \& Silva (2004) que apresentam um Ambiente Cooperativo, baseado na web, que contribui para a aplicação da avaliação de aprendizagem, e se propõem à testá-lo com estudantes a propósito de estabelecer eficácia da avaliação com mapas conceituais em relação aos objetivos propostos pelo professor. $\mathrm{O}$ delineamento da pesquisa sugere que o ambiente construído pelos autores é importante no auxilio à avaliação de aprendizagem significativa. Segundo os mesmos o ambiente estimula o relacionamento entre os conceitos e a formação de proposições entre eles, facilitando a construção de conhecimento sobre um tema em específico. Todavia não encontramos, no relato, critérios capazes de estabelecer a relação entre o experimento realizado e as conclusões dos autores. Seria possível um ambiente estimular a construção de relações entre conceitos? Como julgar se as relações expressas de fato representam construção de conhecimento?

Já Rocha, Jr \& Favero (2004) buscavam um sistema de análise automatizada de Mapas Conceituais. Os autores constataram que estas análises automáticas são passíveis de incertezas devido ao caráter ambíguo que as proposições nos Mapas Conceituais podem ter. Seu trabalho propõe uma estratégia que visa minimizar essa ambigüidade a partir da análise da natureza de inclusividade dos conceitos dentro da hierarquia de um mapa conceitual. A metodologia envolve a utilização de um programa, denominado EBNF, que faz uso de uma coleção de regras gramaticais que, de acordo com o estudo, é capaz de determinar a possível posição das frases de ligação nas proposições de um mapa conceitual. Ao atribuir a tais posições valores relativos a uma gramática arbitrária (entendida aqui como uma tipificação das possíveis frases de ligação), o processamento de um mapa conceitual estabelece uma medida de comparação semântica das diferentes proposições, agrupando-as segundo a gramática utilizada e estabelecendo seu grau de relevância e pertinência. Em um outro trabalho (Rocha, Jr \& Favero 2004b), os mesmos autores apresentam um programa que faz uso de um algoritmo genético e de ontologias computacionais para comparar mapas conceituais referentes a assuntos comuns (que compõem as ontologias) e oferecer sugestões aos usuários de um editor digital de mapas (desenvolvido pelos autores). Como os próprios afirmam em seção específica desse artigo, esse tipo de abordagem difere daquele encontrado na literatura no sentido de promover comparações entre conjuntos de mapas e não apenas com aquele de um especialista no assunto. Trata-se de um trabalho consistente e engenhoso no que diz respeito ao método utilizado para a efetuação das medidas e comparações. Por outro lado, indagamos: é suficiente oferecer sugestões de proposições para os mapas no sentido promover construções conceituais? É possível, apenas por critérios retirados da linguagem ou da sua semântica, estabelecer se as significações expressas pelos sujeitos são equivalentes?

No âmbito das ações descritas nesse trabalho, as intervenções apresentadas na seção anterior têm o objetivo de desencadearem tomadas de consciência (Piaget, 1977, 1978) por parte dos sujeitos (participantes dos cursos) em relação às suas construções (mapas conceituais) e, ao mesmo tempo, em relação às estratégias de uso dos mapas para acompanhar as aprendizagens de seus alunos. 
O modelo de intervenção a distância que ora apresentamos constituem os nossos primeiros resultados no sentido de reunir um conjunto sistematizado de orientações que norteiam a produção de atividades e as técnicas de exploração das possibilidades das relações nos Mapas Conceituais construídos pelos alunos participantes dos cursos oferecidos pelo Portal MCE. Os exemplos apresentados sugerem que é possível potencializar a eficácia das ações implementadas a partir da identificação e planejamento de tais intervenções de tal forma que, ao final de cada ciclo de atividades se possa inferir que houve, de fato, modificação no sistema de significações dos sujeitos (Piaget, 1976b; Piaget, 1995).

É possível, portanto, resumir o conjunto de resultados do estudo a partir da enumeração das seguintes orientações:

- no que diz respeito às atividades, deve-se privilegiar não apenas a construção de mapas conceituais mas, principalmente, a revisão sistemática de cada mapa construído de forma a tornarem cada vez mais explícitas as relações entre os elementos (conceitos em construção) envolvidos em tais produções;

- em virtude do tipo de construção permitida pelos mapas conceituais é fundamental a produção de registros em linguagem natural, por parte dos sujeitos, em relacionados às proposições contidas nas produções resultantes de cada atividade (no caso os mapas conceituais); e

- as trocas sistemáticas (perguntas, pedidos de esclarecimento, entrevistas) sobre os mapas conceituais produzidos com a finalidade de obter o ponto de vista do sujeito que os construiu são fundamentais para as tomadas de consciência a respeito das relações (ou sistemas de relações) expressas nos mapas.

O contraste entre os resultados obtidos no nosso estudo com o levantamento de outros trabalhos nos faz acreditar que os primeiros resultados podem servir de apoio às discussões e investigações que estão acontecendo em virtude da expansão da educação a distância no país e, em especial, para os cursos de licenciatura a distância.

\section{Referências}

Ausubel, D. P (2000). The Acquisition and Retention of Knowledge: a cognitive view. Dordrecht: Kluwer Academic.

Cañas, A. J., Ford, K.M., Coffey, J., Reichherzer, T., Suri, N., Carff, R., Shamma, D., Hill, G., Hollinger, M. \& Mitrovich, T. (1999). Herramientas para Construir y Compartir Modelos de Conocimiento. In: 99 Workshop Internacional sobre Educação Virtual, Fortaleza, Brasil.

Cañas, A. J., Hill, G., Carff, R., Suri, N., Lott, J., Eskridge, T., Arroyo, M., Carvajal, R (2004). Cmaptools: a knowledge modeling and sharing environment. Concept Maps: Theory, Methodology, Technology 2004. First International Conference on Concept Mapping, Pamplona, Espanha.

Cunha, M.J.S., Fernandes, E., Omar, C. T. \& Silva, N. V. (2004). Avaliação de Aprendizagem Significativa Usando Mapas Conceituais num Ambiente Cooperativo. Diversidade e Integração: Desafios para a Telemática na Educação, XV Simpósio Brasileiro de Informática na Educação, Manaus, Brasil. 
Dutra, Í. M., Fagundes, L. C. \& Cañas, A. J. (2004). Un Enfoque Constructivista para el Uso de Mapas Conceptuales en Educación a Distancia de Profesores. In: CMC 2004 - First International Conference on Concept Mapping, Pamplona, Navarra Espanha.

Dutra, Í. M. (2006). Mapas Conceituais no acompanhamento dos processos de conceituação. Tese de Doutorado. Centro Interdisciplinar de Novas Tecnologias na Educação. Programa de Pós-graduação em Informática na Educação. Porto Alegre.

Grize, J. B. (1996). Logique naturelle et communication. Paris: PUF.

Grize, J. B. (1997). Psicologia Genética e Lógica. In Banks-Leite, L. (Org.). Percursos Piagetianos. São Paulo: Cortez.

Inhelder, B. \& Piaget, J. (1976). Da lógica da criança à lógica do adolescente. São Paulo: Pioneira.

Novak, J. D. \& Gowin, D. B. (1984). Learning How to Learn. New York: Cambridge University Press.

Piaget, J. (1976a). Ensaio de Lógica Operatória. Porto Alegre: Globo.

Piaget, J. (1976b). A equilibração das estruturas Cognitivas: Problema Central do Desenvolvimento. São Paulo: Zahar.

Piaget, J. (1977). A tomada de consciência. São Paulo: Melhoramentos.

Piaget, J. (1978). Fazer e compreender. São Paulo: Melhoramentos.

Piaget, J. \& Garcia, R. (1989). Hacia una logica de significaciones. Cidade do México: Gedisa.

Piaget, J. (1990). Epistemologia Genética. São Paulo: Martins Fontes.

Piaget, J. (1995). Abstração Reflexionante. Porto Alegre: Artes Médicas.

Rocha, F.E.L. \& Favero, E.L. (2004). A New Approach to Meaningful Learning Assessment Using Concept Maps: Ontologies and Genetic Algorithms. Concept Maps: Theory, Methodology, Technology 2004, International Conference on Concept Mapping, Pamplona, Espanha. 